\title{
Salutogenesis and the art of sustainability: Help from the 3 C's
}

\author{
Ross M. Bremner, MD, PhD
}

\footnotetext{
From the Division of Thoracic Surgery, Center for Thoracic Disease and Transplantation, Norton Thoracic Institute, St Joseph's Hospital and Medical Center, Phoenix, Ariz.

Read at the 44th Annual Meeting of The Western Thoracic Surgical Association, Goleta, California, June 27-30, 2018.

Disclosures: Author has nothing to disclose with regard to commercial support.

Received for publication Jan 2, 2019; accepted for publication Jan 3, 2019; available ahead of print May 17, 2019.

Address for reprints: Ross M. Bremner, MD, PhD, Norton Thoracic Institute, St Joseph's Hospital and Medical

Center, 500 W Thomas Rd, Ste 500, Phoenix, AZ 85013 (E-mail: Ross.Bremner@DignityHealth.org).

J Thorac Cardiovasc Surg 2019;158:315-22

$0022-5223 / \$ 36.00$

Copyright (C) 2019 by The American Association for Thoracic Surgery

https://doi.org/10.1016/j.jtcvs.2019.01.117
}

To say it has been a privilege to serve as your president is an enormous understatement. This organization has been vital to me since I first presented a paper here as an intern some 26 years ago. I have continued to prioritize my research over the years for presentation at this meeting and have been fortunate to have had our work discussed many times. I would go so far as to say that without this meeting I likely would have written far less and been much less inspired. I have made wonderful friends, as has my family, and I have seen parts of the country I wouldn't have otherwise visited. And perhaps more importantly, I have received advice and encouragement from various mentors who made themselves available to me over the years. I want to thank you all for what you do for the Society and what you have done for my family and me.

Being chosen as your president was not only a surprise, but for me, a daunting task. Like some, I imagine, I have felt unworthy of the position, but to tell you the truth, I have loved every minute of it. I am truly grateful to have had this opportunity-I consider it the pinnacle of my career, so I thank you. Having said that, I am reminded of an old Chinese proverb: "The higher you climb, the more you show your arse," so I will try not to show too much of it today.

This past year as president has been exciting as I have learned about the Society from a different vantage point, and have understood more fully why it is so important to so many of us. We do so much really well here. Despite murmurings of the meeting being too long or too short, too expensive or too far, the poll of our members has shown little room for improvement. I sincerely hope that, in spite of various financial challenges and other obstacles, we continue to have a meeting that balances friendship, family, fun, and science.

There are people, some who have made a great effort to be here today, who merit a special mention as they have helped shaped who I am and who remain models of who I

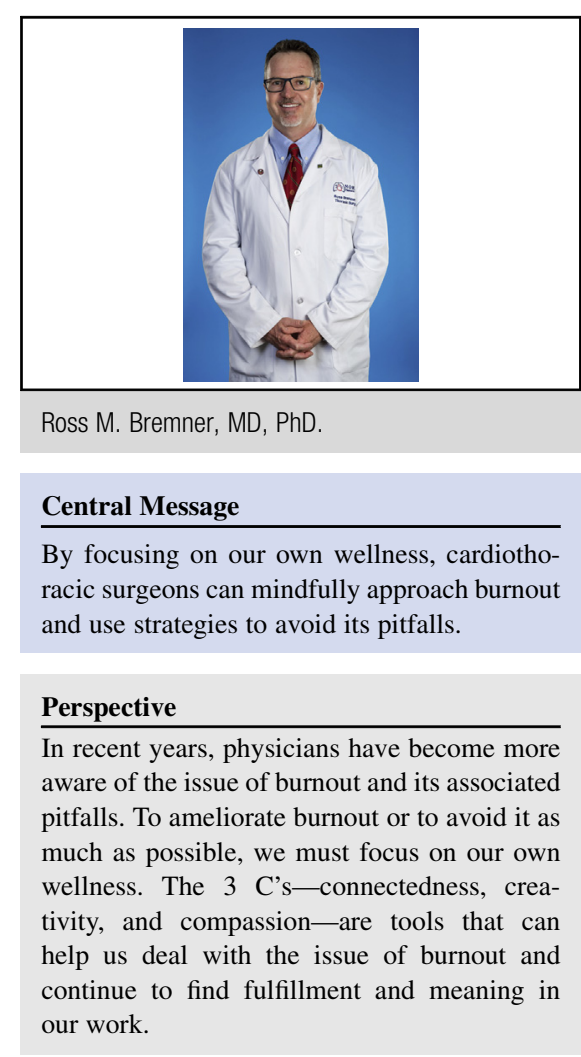

aspire to be. I would like to recognize them knowing that I cannot possibly mention all those who have helped me.

I first need to thank my high school principal, Mr Oliver Cromwell Wigmore, who dissuaded me from a career as an architect and steered me toward medicine. At medical school, I was exposed to some of South Africa's great physicians and scientists: Dr Phillip Tobias, the dean of my medical school, was an antiapartheid activist who was thrice nominated for the Nobel Prize. He allowed me to take a break from my first year at medical school to spend a year in Houston as an American Field Scholar. That year abroad shaped my life. Thanks also to John Barlow (of Barlow syndrome) who taught me the importance of the clinical exam, and Burt Myburgh, a Springbok athlete and surgeon of both the first kidney and liver transplants performed in South Africa.

I need to pay special gratitude to Tom DeMeester, who after an evening of good food and even better wine at the World Organization for Specialized Studies on Diseases of the Esophagus meeting in 1990, offered me a position 
in his residency at University of Southern California (USC). It is through Tom's generosity and kindness that I came to live in the United States. Tom taught me how to slow down my thinking, to be precise in my writing, and to be a true champion for my patients. Thank you to Vaughn Starnes for teaching me to be precise in surgical movement, to keep my operations simple, not to get frustrated, and for reminding me that if it looked easy, I was probably doing it right. Last month Niles Chapman died. He shared a career of experience with his residents as a voluntary faculty at USC, and for this I am extremely grateful. I also learned an incredible amount about life and surgery from Robbin Cohen, who was among my teachers at USC and who continues to be a mentor and close friend. Thank you, Robbin.

I have made a number of dear friends at the Western and I am grateful for your continued friendship. I would like to specifically thank John Handy for reminding me to live my life on purpose, and John Mitchell, for setting the example to always pause before giving a measured opinion. A special thank you to Leah Backhus for making this meeting what it is-it has been a tremendous amount of work. To see all you are accomplishing in your academic life after spending a brief stint in my lab at USC makes me incredibly proud. Thank you, Robbin and Shannon, for all the work done as local arrangements chairs and a big thanks to Jon's team for the diligence in making this meeting as special as it is. And thank you to the whole council, who have helped guide me through this experience.

I would like to also thank John Nigro for his vision of what could be accomplished in Phoenix, and to my whole team at the Norton Thoracic Institute, especially those who made a special effort to be here. It means an incredible amount to me. To my partners, thank you for your talent, energy and your continued support. And to Michael Smith, my partner for now 14 years, you have no idea how much I appreciate your tireless support, your thoughtful opinions, your surgical skills, and your leadership of our transplant team.

Finally, there are the people who love me no matter my shortcomings. My parents are here tonight, having flown all the way from South Africa. Mom, thank you. You always believed in me more than I believed in myself. Thank you for teaching me the value of compassion. Dad, you taught me most of what I know. Your hours of teaching me and our group at medical school instilled in me a love of anatomy and physiology and an understanding of how crucial they are to good surgery. You have always inspired me and I can only hope to one day achieve your level of grace. To my baby sister Heidi, thank you for all your encouragement over the years and for your constant nagging about my terrible posture. And to my other siblings and their families who live in South Africa-thanks for tolerating me as long as you have and for spoiling me whenever I visit home.
I recently read the American Association for Thoracic Surgery book of interviews of past presidents. Almost to a fault, each of them attributed their success in large part to the dedication and understanding of their wives. I believe Kathy is the queen of these phenomenal women. She has stood by me through thick and thin, even moving our family to the so-called surface of the sun with unwavering support. She has helped me put things in perspective, and has reigned me in when I got involved too deeply in business matters. She has managed, through it all, to keep me laughing. I find myself more in love with her every day. And I doubt my 2 children could have found a more loving mother. Thank you my love. To Kensey and Ashley-I love you kiddos. You have no idea how proud I am of you. Kensey, may college be all you hope it to be. Ashley, I look forward to you being the "only child" for the next 2 years. I know you both have sacrificed your opportunity to compete in the Junior Olympics synchronized swimming competition to be here. It means a great deal to me, so thank you.

Although somewhat daunted by the task of addressing you, I have been looking forward to talking to you this morning. Robbin Cohen told me that there are few times in life when you get to talk about anything you like and your audience just has to listen. And Scott Millikan advised me to "just talk from the heart."

So, here goes....

\section{BURNOUT: A PREVALENT OGRE}

Before I begin, I want to ask you all for a favor. Please all stand up. Now place your hand on your heart, take in a deep breath. Close your eyes. Now breathe out slowly.

Thank you, you can sit down. Gosh, that was fun. Although I want to have a conversation this morning that addresses some difficult problems, I promise you that the hand on your heart thing is the most uncomfortable I will make you feel. But thank you for indulging me.

You see, I believe we as physicians have a problem. And that problem is probably greater for those of us who practice cardiothoracic surgery. Our hearts are not well. We are going to need to evolve to save ourselves and to save that which makes our profession so important to our communities. There is much at stake.

In a survey published last year by Medscape, $51 \%$ of physicians reported feeling "burned out," up from $40 \%$ only 3 years previously. ${ }^{1,2}$ A more recent Time article featuring Toby Cosgrove put that number closer to $70 \%{ }^{3}$ Fifty-four percent of us feel "emotionally exhausted," while a mere $14 \%$ of doctors feel they have "enough time" to provide optimal patient care. Sixty-nine percent of us now feel our autonomy has significantly decreased in the face of increasing time needed for non-clerical paperwork, which now consumes $21 \%$ of all our time. , $^{2,-6}$

Burnout as described initially by Maslach and colleagues $^{7}$ is characterized by emotional exhaustion, 
cynicism, depersonalization, and a low sense of personal accomplishment. Nasty stuff. It may last indefinitely and clearly has significant implications on the health of our physician body and the ability to provide optimal care for patients. Burnout is said to be behind the high incidence of substance abuse, divorce rates, and suicide in our profession. Four hundred of us commit suicide every year-that is equivalent to 3 medical school graduating classes each year! ${ }^{8,9}$ In an American College of Surgeons survey, 14\% of male surgeons and $25 \%$ female surgeons admit to alcohol abuse ${ }^{10,11}$ (perhaps the women are just more honest!), and a quarter of us get divorced. The prevalence of burnout in the medical profession is now thought to be almost double that of any other profession. We, who are fighting for the health of our patients, are often unwell at the core. Who will fight for us?

You see, in the midst of our increasing bureaucratic responsibilities, the decreasing autonomy of physician specialists, the decrease in public trust, the need to adapt to complicated and counterintuitive electronic health records, and the constant fight to find enough time in the day to do that which needs to be done, the risk of burnout in medical professionals in general is extremely high. All these stressors take away from the meaningfulness of our work. Add to this the constant uncertainty of the future of both reimbursement and the environment of health care, and I would argue that burnout is inevitable-to all of us-at some stage. And the cost to us, our families, our patients and our communities is profound.

Up until a few years ago, the concept of burnout in our profession was not well recognized, and certainly was not talked about much. But since the recent articles by Balsch and colleagues, ${ }^{12,13}$ Shanafelt and colleagues, ${ }^{14-16}$ and others, and an increase in awareness in social media, the term burnout has entered the conversation.

Today, I want to take a few minutes to discuss this issue, and then to turn our attention to burnout's antonym: wellness. I also want to ask: What can we, as a Society, learn about the problem of burnout and, more importantly, what can we as cardiothoracic surgeons do about it? Mastery is at the core of our profession, and it's time to turn our attention to mastering this chronic condition that afflicts us.

Let's start with the obvious: What we do is hard. It is extremely demanding physically and emotionally, and the forces that drain our batteries are so much greater than those that currently exist to recharge them. An all-night lung transplant, a redo arch replacement, a substernal colon interposition, a Norwood procedure, and the intensity of the perioperative care of all these patients requires a good deal of physical energy. And when our patients experience complications or have a poorer-than-expected outcome, our emotional gas tank empties pretty quickly. When our batteries are depleted, our resilience is gone. Small problems appear insurmountable and we are quick to anger and slow to listen. We become compassion-fatigued and everyone suffers.

Burnout has now been associated with disruptive behavior, rudeness in the operating room and on the wards, poorer clinical outcomes, and more medical malpractice suits. ${ }^{15,17,18}$ From a business perspective, there is now a growing body of evidence of the scope and expense associated with physician burnout, which is a leading cause of physician turnover in an institution. Replacing a physician is estimated to cost between $\$ 500,000$ and $\$ 3$ million-numbers that have finally gotten the attention of our institutions. ${ }^{19}$ For this and other reasons, there is growing interest in both burnout and wellness in medical education (yes, millennials too experience burnout) and among some of our organizations. In fact, our own Hippocratic Oath was changed a few months ago by the World Medical Association to recognize the problem. ${ }^{20}$ The following language was added: "I will attend to my own health, well-being, and abilities in order to provide care of the highest standard." ${ }^{20}$ Of course, this puts the onus back on the physician without tools to support the pledge, but the good news is that physician well-being is now getting some attention.

So how do we attend to our own well-being as we are now charged with doing? Indeed, do we even know what we are aiming at? The Merriam-Webster dictionary defines wellbeing as "a state of being happy, healthy, and prosperous" (very nice!). Psychologists point out that wellness is quite poorly defined, although it has physical, economical, psychological, sociological, and spiritual elements. It is not merely the absence of disease. In my mind, it is an experience of satisfaction and peace that supports my full engagement in all aspects of my life. We may all define it slightly differently but for purposes of this discussion, let's consider it the opposite of burnout.

The research suggests that to combat burnout, we need to look at increasing resilience. But we are already pretty resilient people. Grit has been drummed into us. We have been taught that our work requires extraordinary commitment and significant self-sacrifice. So we toughen up with the adages we are all so used to: "The patient ALWAYS comes first," "You don't need to eat every day," "You can sleep when you die," "To ask for help is a weakness," and "The only downside of doing every other night on call is that you miss half the good cases." We have all said these things, perpetuating the image of surgeons as selfsacrificing gladiators who do not whine and do not admit to weakness.

However, while we burnish our armor, we separate ourselves somewhat from the patient. We focus on the disease and offer a superficial, comforting smile-all the while protecting our valuable time and an even more scarce resource: Our emotional engagement. This tendency, which intensifies over time, deprives our patients of our compassion 
and deprives us of meaning and connection. Rather than moving us toward resilience, it exacerbates that which depletes us and limits one essential resource to replenish us. As it turns out, gladiators get exhausted too.

\section{MY STORY}

I'd like to tell you a personal story. And while I initially felt my story was unusual, I now realize from conversations I have had over the last year that many of you will be able to relate. And, yes, being vulnerable is hard and uncomfortable, so please give me a little latitude.

About two-and-a-half years ago, I woke up one morning and, for the first time in my career, I had no interest in going to work. I had been working so long and so hard that I felt completely spent. The year had been a particularly hard one. Our transplant program had unexpectedly ballooned (and was consequently under-resourced), and we had a complete turnover of our medical group administrators. These new administrators had little understanding of our service line or culture. This caused all sorts of concern in my overworked faculty, to the point where many were considering leaving. All that we had built over 10 years was threatened. I had to come up with a solution for all of us, and finally managed, using all the political and mental capital I had, to forge another reporting structure for us with the hospital, and to renegotiate all of our contracts. I was unfriended by a number of the medical group administrators, of course, which bothered me more than I thought it would. There were increased stressors at home. And during all this I injured myself and needed surgery, and learned that it's not that fun to be at the other end of the scalpel. To be physically broken was much harder than I expected.

An accumulation of all those years of sleep deprivation, work stress, and neglect of my own needs had left me completely depleted. I didn't want to do it anymore. And yet, I continued to drag myself to work, to put on a good face (I thought), and to drag myself home at the end of the day. I slowly realized that I had become anhedonic. I could not find pleasure in anything - even watching a movie with my kids was bland and uninteresting. I became absent to both my patients and my colleagues at work. I was not a part of my own family, who I now realize were dealing with life and its various challenges on their own. I could not see outside the hole I had found myself in. In the back of my mind, I realized that I was experiencing this burnout thing I heard being discussed. I remember finding an article in STS News entitled: "Physician Burnout: A Growing Phenomenon, A Call to Arms." ${ }^{21}$ And in the corner was an advertisement for an upcoming Society of Thoracic Surgeons session entitled Physician Resilience. I put it on my nightstand to read one evening. It stayed there, unread for months and getting its fair share of coffee stains, right next to "Peak" and "Flow." I planned to attend the session and figured that if I attended I would be given the tools needed to fix all this.

In the interim, I remained physically and emotionally exhausted. I began to experience depersonalization, and I lost a sense of meaning in my work. I remember walking down the hospital hall one day perseverating over a postop esophagectomy patient who had just had a high fever when a couple walked by me. The woman, wearing a mask, turned to me "Dr Bremner, I just wanted to thank you-you did my transplant 3 years ago and I'm doing fantastic. I cannot tell you how grateful I am to you and all of your team."

"Ah, you're welcome, it's what we do," I replied, my thoughts still on the sick patient in intensive care. And off I walked, completely unaffected by this heartfelt expression of gratitude. Still running on empty.

I had no idea where to turn for help. "Asking for help is a weakness" was a residency mantra, right? Our culture did not allow for this sort of thing. I figured I would just have to shake it off. But I knew that something was wrong. Small things at work bothered me more than they should have. Surgical complications kept me awake more than they had before. The gratitude expressed by patients for good outcomes fell on deaf ears. And while I never was a very good listener at home, I switched off almost completely. I needed to talk to someone, but had no resource. Google wasn't much help either. One site suggested I "ask why, then take a vacation," and another of course recommended that I "practice positive thinking!" My wife repeatedly suggested that I talk to a counselor and I eventually went to see a psychologist who had helped some friends of hers. I felt guilty and ashamed and more than a little weak as I snuck out of the hospital to my appointment at the end of another long day. I even paid cash so that there would be no credit card paper trail!

Unfortunately, this help was not actually helpful. After an hour (that felt much longer) of me exposing my vulnerability more than I ever have in my life, I got no advice, but only a question as to when I wanted to schedule my next session! Disappointed that I had not been given the keys to cure burnout on the spot, I defaulted to what I was trained to do-figure it out for myself. I bought 10 copies of a book called Stop Physician Burnout: What to Do When Working Harder Isn't Working 22 for me and my colleagues and tried to read it. I got stuck pretty early on with "the squeegee breath."

Then my brother got sick. After months of going to his primary physician with enlarging groin nodes, a biopsy finally revealed anaplastic large cell lymphoma. I'd never even heard of this beast, but a beast it was. Although I learned a lot about it very quickly, I didn't know what advice to offer him. So I called some of my friends and colleagues around the country. Some of you are here today. And I learned again how gracious and generous my 
colleagues can be, and I found the help and guidance we needed. Even with this help, I felt completely responsible for providing my brother the information he needed so that he would get the right chemotherapy and the right advice for a stem-cell transplant should that be necessary. We learned that the disease has 2 major categories, Alkpositive, and Alk-negative. Alk-positive has a very good prognosis. Alk-negative not. And Bruce's tumor turned out to be Alk-negative. It looked grim.

Of course, worrying about Bruce did little to relieve the stressors at work. As I saw more clearly the symptoms of burnout I was experiencing, I also started recognizing signs of burnout in my colleagues. Disrespectful outbursts that were out of character from some of them, and being withdrawn and disinterested at meetings in others. And I realized that by helping myself, I might be able to help them. The truth is, framing my efforts as an act of service rather than an act of self-care made it easier for me to continue my search for resources.

About this time, I attended that Society of Thoracic Surgeons meeting and found significant value in a resilience session, but I was still standing at the base of a very large mountain. At the meeting, I ran across a young surgeon whom I had met recently at a local cancer conference. He was barely a year or two into practice and out of the blue he asked me a question. "You seem so balanced," he said. "How do you manage to do all you do and yet have balance in your life?" Immediately I thought of the Charlie Brown cartoon with Snoopy admitting that his peaceful façade was merely covering up his internal turmoil. I had little to offer, except to tell him to make sure he takes some time for himself. As I walked away, I realized just how hypocritical that was.

Upon my return to Phoenix, I got serious about finding help. I serendipitously read an essay from Atul Gawande on surgical coaching. ${ }^{23}$ I made some inquiries and was put in contact with an executive leadership coach. Slowly, she helped me peel back the layers of the onion to better understand my demons so that I could once again get back on the path to being the excited, energetic, compassionate doctor that I had always considered myself to be. To be sure, this is a work in progress. I backslide regularly, but I remain extremely grateful for all the help she has provided.

There are some key takeaways from my work, which I will share in the hope that my experience can provide some tools to help each of you, regardless of where you are in your career.

\section{OBSTACLES}

Before turning to what I think can be done, let me address 2 obstacles that get in the way of doing anything.

\section{Obstacle Number 1: Time Poverty}

Time poverty was a big issue (and excuse) for me, as it is for many of you. As surgeons, time is a scarce resource and what little there is seems only marginally within our control. We are not alone in this. Many of my musical heroes have sung about it. And while we would love to feel the way James Taylor does, "The secret of life is enjoying the passing of time," we really relate more to Steve Miller- "Time keeps on slipping, slipping, slipping into the future." We are slaves to time.

You think you are good at time management? Well, most of us have a poor sense of it. In a recent survey I conducted in a large group of anesthesiologists in Phoenix I found that we, as surgeons, often estimate time poorly. I asked a single question: "When a surgeon tells you the surgery will be completed in 30 minutes, how long do you think the case will actually take?" Their average answer: 53 minutes. Almost double. There has to be a lesson there for us. Because we just put ourselves $23 \mathrm{mi}-$ nutes behind the rest of our day. It only takes a single unforeseen surgical emergency to put us behind the 8-ball. Time management is incredibly difficult when there are so many unpredictable interferences in our lives.

So I propose a thought for your contemplation: We are not superhuman, and we cannot get things done in less time than they actually take. Be a little kinder to yourselves. There are days when everything will go as planned, but these days are extremely rare. Build some space into your concept of what can be accomplished in any specific time period. Don't set yourself (or others) up for unnecessary wear and tear. Realize that you may have more control than you think. My coach challenges me with the ultimate goal of having an "effortless relationship with time." If only....

\section{Obstacle Number 2: Lack of Tools and Expertise to Handle Burnout}

We are used to being experts. But we lack the tools and the expertise to deal with this problem. One of the challenges with resolving burnout is we often don't fully understand what's happening. Rather than admit that we are at a loss to fix it or to even articulate the problem, we put our heads down and hope that it will go away. Statistics tell us that is usually doesn't.

One of the best ways to move toward sustainability is to educate ourselves on these issues, to adopt frameworks for analyzing and solving for problems like burnout. To that end, I'd like to introduce you to Aaron Antonovsky, a researcher who gave me an intellectual framework for understanding where I was and what I could do about it. Antonovsky was a social psychologist born 1923 and educated at Yale. He developed a theory of health in his interest to understand how some people cope with certain stressors in life.

We are taught, in medicine, a certain concept of disease. Our goal as physicians is to combat physical illness. However, according to Antonovsky, our degree of health exists 
in a continuum of ease and dis-ease. ${ }^{24} \mathrm{He}$ coined the term salutogenesis in describing an approach focusing on factors that support human health and well-being, rather than on factors that cause disease-what we refer to as pathogenesis.

We have little time to discuss Antonovsky's life's work, but he helped us understand that our sense of coherence (or wellness) depends in large part on our relationships with family and friends, as well as our ability to tap into our resilience mechanisms. We all have an innate desire for a good quality of life. And when we experience that quality of life, we are nicer, we are more effective and we behave better. In other words, a happy doctor has a better chance of being a good doctor than a stressed or demoralized one. We can all agree on that. And we now have lots of data to support it. So let's educate ourselves and have a real conversation about what we can do to deal with this widespread sense of dis-ease that plagues us.

No doubt the forces that drain us will remain. We will have long nights, tough outcomes, and legal challenges, not to mention added bureaucratic tasks. For things we cannot change (take health care reform, for example), we need to be nimble, and try to minimize the pain they incur. At the same time, we should be working within our institutions to design systemic solutions to change this condition, or to at least mitigate it where we can. Many of you have or can have a voice at the table to drive this sort of organizational change. Wellness programs are gaining traction at places like Stanford, Cleveland Clinic, Mayo Clinic, and Kaiser Permanente, all of which have recently initiated physician wellness programs. It is critical that we as cardiothoracic surgeons participate, or we run the risk of having others drive potential solutions for us. The National Institute of Medicine, in collaboration with the Association of American Medical Colleges and the Accreditation Council for Graduate Medical Education, very recently launched "The Action Collaborative on Clinician Wellbeing and Resilience" to promote both awareness and information sharing. ${ }^{25}$ Only recently, we initiated discussions on establishing our own wellness program at St Joseph's Hospital and Medical Center in Phoenix. There are many hurdles (time and stigma probably being the biggest), but I am excited at the potential that this program can bring to our organization.

\section{SOLUTIONS}

These wellness programs will, I hope, start to expand the conversation about where we are and how we need to change, but change will not come easily or quickly. Research into this problem is burgeoning, and articles on the subject are beginning to appear in the literature, ${ }^{26-29}$ offering ways to decrease bureaucratic burden, improve workflow, and increase autonomy. But these will not be overnight solutions. So I will leave you with my big 3 takeaways from the past 2 years of working on and through these issues. They have been critical to reestablishing, for me, a sense of equanimity. I call them "The 3 C's," and I believe they hold clues to our mastery of the stressors that lead to burnout, and that with attention to these we can swing our see-saw in a direction where we can feel happier, more productive, and more in control of our lives. Next year when someone asks what Bremner talked about, please at least remember "The 3 C's."

\section{Connectedness}

When I think about what is most important to me about the Western Thoracic Surgical Association, it is the connectedness that I feel with all of you. When I think about my partners at work, and what I regard as most important to the fabric of our group, it is the connectedness of all the individuals who work there. The same is true with my immediate and extended family. We are willing to help and be helped by others. We strive to make each other better, and in so doing, we elevate ourselves. When we are well, we rarely feel alone or lonely. We, as human beings, are hardwired for connection. Sometimes we seek connection through work, sometimes through personal relationships, sometimes through faith or a commitment to shared activities. Whatever the path, connection gives us some sense of shared purpose.

The loss of connection to these various purposes leaves an emptiness and, left unattended, may ultimately lead to feeling deeply disconnected from our very selves and our lives. If this sounds dire, that's because it is. If it sounds amorphous, well, it is that as well. So you can see why our inability to ask for help or to articulate a problem for which there is no obvious fix can be very hard for us, given our "solve it and be strong" culture. But I remain extremely optimistic that our connectedness can keep us strong. Especially in this challenging time of increasingly divisive rhetoric that is threatening our country's culture. Three of this Society's values echo connectivity: scientific endeavor in a collegial environment, development of young surgeons, and focus on family and friends! Clearly we have recognized the value of connectedness, but perhaps there is more that we can do.

\section{Creativity}

How many of you think of yourselves as creative people? How many of you used to think you were more creative than you do now? I know that so many of you have hidden talents, whether they are artistic, musical, athletic, or otherwise. Some of you have managed to keep your creative outside spirit alive, although I suspect you all wish for more time at it. However, our profession offers us ample opportunities to create. Every patient is different. We learn new things through experience and training throughout 
our careers. So it's not correct to say we lose our creativity. Perhaps it is more intuitive to say we lose our sense of ourselves as creative people, and we invest less and less time deploying our imagination. We go on autopilot. We forget just how many choices this privileged, amazing career we have chosen offers.

One of the challenges I faced over the last couple of years has been re-engaging my imagination. Not all of this, of course, has to do with our profession. Some of it comes with this time of life, as Jim Fann so eloquently discussed last year. Kathy and I are contemplating what it will be like when our beautiful daughters move out into the world - one this fall, and one in two years. I am trying to expand my viewfinder to reimagine my work life and to question the assumption that it automatically comes with certain limitations.

Someone asked me recently how much time I spend outside in nature, which is something that has always been important to me. I was proud to say I make it a priority to spend at least 20 to 30 minutes running outside, 6 days a week. I thought this was a major accomplishment, but it made me ask myself: When did I decide that spending just 3 of the 168 hours available to me each week constitute "making it a priority"? When did I decide that I had little control to prioritize my time? I love my job. I feel privileged to do it. But it struck me that somewhere along the line the demands of work, I put my creative side on the back-burner. I have realized that it is important to pick up my paintbrush and my guitar-before retirement. Because I understand how energizing it is to exercise the creative aspects of our brains.

So recognize your creativity at work, in the surgical procedures you do, in the management of your patients, in your interactions with colleagues and administrators, and in the multiple opportunities you have to be creative outside of work. Ronald Belsey said that he was most proud of the last page of his curriculum vitae, which dealt with his hobbies and outside activities. Perhaps we should take a page out of his book.

\section{Compassion}

The last $\mathrm{C}$ is a word we throw around quite often: compassion. It has come to mean the kind, caring feelings we feel or are supposed to feel for every patient who is suffering. If the truth be told, our compassion is not always fully present. Whether through coping mechanisms like compartmentalizing and numbing, frustration with patients who are not helping themselves, or through sheer fatigue, we sometimes lose our compassion. We find it hard to connect with those kind, caring feelings that are supposed to come with our white coats and stethoscopes.

While I was trying to climb out of that hole that I had dug myself into, I found myself moved by an advertisement on television one evening. A young kid helping a player on the other team get up during an ice hockey game! It struck me that this compassion thing was a big part of why I do what I do, and that perhaps I was not tapping into the full potential of what compassion can offer to my patients, to my family, and to myself.

To get back to the story of my brother Bruce (the short version): Although his cancer was Alk-negative, I subsequently learned that he had a favorable gene rearrangement that would enable him to avoid a bone marrow transplant if he responded well to chemotherapy. He did indeed respond well, although I can only imagine what it felt like to vomit for days on end, to be unable to eat or to sleep, and to lose 25 $\mathrm{lb}$ that were not there to lose in the first place. But Bruce's positron emission tomography scan was clean in February this year, so in March he climbed to base camp at Mount Everest. A bucket list thing for him, I guess. Perhaps we could take a page from his book, too.

I was so overjoyed and relieved to see his clean scan that I called his oncologist (a classmate of mine from medical school).

"David," I said, "I want to thank you for all you have done. You have no idea how grateful we all are."

"No problem," he replied. "It's what we do."

This was exactly the response I had given to the patient I passed in the hall a year earlier. How often do we say the same? And yet, I so badly wanted him to know the depth of my gratitude. What each of you do on a daily basis changes peoples' lives. Your sacrifice of time, family, and yourself for others is often recognized by your patients. Take a moment to accept gratitude. Accept that heartfelt handshake or that hug for all it is intended. This is the one thing that takes absolutely no extra time, but has an incredibly powerful and positive healing effect.

\section{CONCLUSIONS}

So, as we go forward, I would like you to spend a little time reflecting on The $3 \mathrm{C}$ 's. We have to recognize the dangers of burnout, but more importantly, we should be working toward our own ease and wellness. Stay connected with your peers, your family, your friends, because it will keep you grounded. Recognize creativity in your work, and take a little time to be creative outside the workplace-it will keep you energized. And finally, recognize the power of compassion—give it to yourself, to your patients, and to your teams, for it will continue to give you meaning in all you do.

As part of my presidency, I have floated the idea of having a formal mentorship program within the Western Thoracic Surgical Association. The council and others have warmed to the idea. I, personally, have found mentors here within the Society over the past 26 years, but too frequently I felt I was imposing on them, only to find out later that the experience was mutually beneficial. We are a very connected Society. We have, among our values, the nurturing of young surgeons. Going forward, and with the help of some of 
you, we will take this concept to the next level, providing tools for mentorship and the infrastructure to connect young surgeons with sage experience. I urge you to consider being either a mentor or mentee in this program. I hope we can continue our discussion on issues like burnout and wellness; these issues reveal both our human vulnerability and our incredible resilience. I believe this is an important way that we can promote wellness in ourselves and in our Society.

I thank you again for your time and for the incredible honor of being your president. I hope you fully enjoy all this meeting has to offer.

\section{Addendum}

It has been nearly a year since I delivered this address. A number of surgeons and surgeons' spouses tell me that it resonated with them and that they were grateful that the conversation was started. However, I have been somewhat reluctant to submit it for publication for 2 reasons.

The first reason is personal. It is one thing to bare one's soul to a group of close friends such as I have in the Western Thoracic Surgical Association, and quite another to do so in writing for all to read. I am hoping that the published version can convey at least some of what came across in my spoken address and that it will resonate with some of you in this broader audience.

The second reason I hesitated to publish this was my concern that this burnout thing was really just a passing conversation, that it would soon be forgotten, and that I was making too much of it. It took me a while to realize that this desire to minimize the issue-to convince ourselves that we can simply handle it with some publications, presentations, and ad hoc conversations-is part of what got us here in the first place. We simply do not want to dive deep into these areas where we feel less than competent or, dare I say, weak. It's symptomatic of the warrior culture that brought us here, and only by pushing through our internal resistance to talking openly about it, for ourselves and for our profession, will we be able to bring real change into our community, our organizations, and our lives.

This problem is real and we are only beginning to understand its scope and impact. Since my talk there have been numerous excellent publications exploring the issue. I am confident that we can and will find solutions for physician burnout, and I am grateful to everyone who can open their minds to the issue and embrace a dialog that will lead us to solutions. I believe that our profession is a gift to us and our patients, and that as dexterous, compassionate physicians, we make a real difference in this world. I truly hope we can all experience what that means to the fullest extent.

\section{References}

1. Peckham C. Medscape national physician burnout \& depression report 2018. Available at: https://www.medscape.com/slideshow/2018-lifestyle-burnoutdepression-6009235. Accessed February 15, 2019.
2. Shanafelt TD, Hasan O, Dyrbye LN, Sinsky C, Satele D, Sloan J, et al. Changes in burnout and satisfaction with work-life balance in physicians and the general US working population between 2011 and 2014. Mayo Clin Proc. 2015;90:1600-13.

3. Sifferlin A. Two-thirds of doctors experience burnout. Here's how to stop it. Available at: http://time.com/5207403/fixing-doctor-burnout/. Accessed February 16, 2019.

4. Martin M. Physician well-being: physician burnout. FP Essent. 2018;471:11-5.

5. Valentine RJ. The hidden cost of medicine. J Am Coll Surg. 2017;225:1-8.

6. Woolhandler S, Himmelstein DU. Administrative work consumes one-sixth of U.S. physicians' working hours and lowers their career satisfaction. Int J Health Serv. 2014;44:635-42.

7. Maslach C, Schaufeli WB, Leiter MP. Job burnout. Annu Rev Psychol. 2001;52: 397-422.

8. Balch CM, Bechamps G. Substance abuse among surgeons: the perils of losing your credentials. Arch Surg. 2011;146:1291-2.

9. Sansone RA, Sansone LA. Physician suicide: a fleeting moment of despair. Psychiatry (Edgmont). 2009;6:18-22.

10. Oreskovich MR, Kaups KL, Balch CM, Hanks JB, Satele D, Sloan J, et al. Prevalence of alcohol use disorders among American surgeons. Arch Surg. 2012;147:168-74.

11. Oreskovich MR, Shanafelt T, Dyrbye LN, Tan L, Sotile W, Satele D, et al. The prevalence of substance use disorders in American physicians. Am J Addict. 2015;24:30-8.

12. Balch CM, Shanafelt T. Combating stress and burnout in surgical practice: a review. Adv Surg. 2010;44:29-47.

13. Balch CM, Shanafelt TD, Dyrbye L, Sloan JA, Russell TR, Bechamps GJ, et al. Surgeon distress as calibrated by hours worked and nights on call. J Am Coll Surg. 2010;211:609-19.

14. Shanafelt T, Sloan J, Satele D, Balch C. Why do surgeons consider leaving prac tice? J Am Coll Surg. 2011;212:421-2.

15. Shanafelt TD, Balch CM, Bechamps G, Russell T, Dyrbye L, Satele D, et al. Burnout and medical errors among American surgeons. Ann Surg. 2010;251: 995-1000.

16. Shanafelt TD, Balch CM, Bechamps GJ, Russell T, Dyrbye L, Satele D, et al. Burnout and career satisfaction among American surgeons. Ann Surg. 2009; 250:463-71.

17. Balch CM, Oreskovich MR, Dyrbye LN, Colaiano JM, Satele DV, Sloan JV, et al. Personal consequences of malpractice lawsuits on American surgeons. J Am Coll Surg. 2011;213:657-67.

18. Welp A, Meier LL, Manser T. The interplay between teamwork, clinicians emotional exhaustion, and clinician-rated patient safety: a longitudinal study Crit Care. 2016;20:110.

19. Rosenfeld J. Calculating the financial costs of physician burnout. Available at: https://www.medicaleconomics.com/medical-economics-blog/calculating-financ ial-costs-physician-burnout. Accessed February 19, 2019.

20. Parsa-Parsi RW. The revised declaration of Geneva: a modern-day physician's pledge. JAMA. 2017;318:1971-2.

21. Lancey R. Physician burnout: a growing phenomenon, a call to arms. Available at: https://www.sts.org/publications/sts-news/physician-burnout-growing-pheno menon-call-arms. Accessed February 16, 2019.

22. Drummond D. Stop physician burnout: What to do when working harder isn't working. Collinsville, MS: Heritage Press Publications, LLC; 2014.

23. Gawande A. Personal best. Available at: https://www.newyorker.com/magazine/ 2011/10/03/personal-best. Accessed February 16, 2019.

24. Eriksson M, Lindstrom B. Antonovsky's sense of coherence scale and its relation with quality of life: a systematic review. J Epidemiol Community Health. 2007; 61:938-44.

25. National Academy of Medicine Action Collaborative on Clinician Well-Being and Resilience. Home page. Available at: https://nam.edu/initiatives/clinicianresilience-and-well-being/. Accessed February 16, 2019.

26. The physician burnout crisis. Available at: https://www.lightning-bolt.com/ physician-burnout-crisis/. Accessed February 16, 2019.

27. DeChant P, Maslach C, Shanafelt T, Weiner K, Mohta NS, Prewitt E. NEJM Catalyst Roundtable Report: seeking solutions to physician burnout. Available at: https://catalyst.nejm.org/roundtable-solutions-to-physician-burnout/. Accessed February 16, 2019.

28. Marcus H. Physician burnout: defining the problems, revealing the solutions. The Doctor's Advocate. 2018; Second Quarter 2018.

29. West CP, Dyrbye LN, Shanafelt TD. Physician burnout: contributors, consequences and solutions. J Intern Med. 2018;283:516-29. 